\title{
IMPACT OF CLIMATE CHANGE ON ELDERLY HEALTH
}

\author{
V. Kalaiyarasi \\ Research Scholar, Department of Sociology, Madurai Kamaraj University, \\ Madurai, Tamil Nadu, India \\ Dr. P. Rajkumar * \\ Professor, Department of Sociology, Madurai Kamaraj University, \\ Madurai, Tamil Nadu, India. \\ * Corresponding author
}

\begin{abstract}
Changes in the usual climate of the planet by global warming leads to climate change. Climate change threatens human health both directly and indirectly through increasing temperatures, rising sea levels, extreme weather events like floods, droughts and earthquakes etc., Climate change threatens the human health especially elderly who are more prone to vulnerability. To analyze the various impact of climate changes on the health of the elderly. This article mainly based on the secondary sources from the national and international articles, journals and reports related to elderly, aging, gerontology, environment and climate change. It covers the impact of global climate change on elderly health in national and international scenario. Extreme heat and winter, Hurricanes, heavy rainfall and flood, air pollution, illness caused by contaminated water and impact of location are the factors under climate change resulted more vulnerability to the elderly on health aspects since their immunity and resistance become very less led to quick accumulation of health diseases and infections to them. Health systems are to be incorporated by expecting the unexpected for the elderly by doing the surveillance on various diseases and by adopting early monitoring and preventive measures according to the climate changes
\end{abstract}

Key words: Climate change, impact, elderly, health, vulnerability, diseases

Cite this Article: V. Kalaiyarasi and P. Rajkumar, Impact of Climate Change on Elderly Health, International Journal of Management, 11(12), 2020, pp. 1273-1278. http://iaeme.com/Home/issue/IJM?Volume=11\&Issue $=12$

\section{INTRODUCTION}

Changes in the usual climate of the planet over a long period of time by global warming leads to climate change. The average global temperature in the earth's atmosphere is maintained by 
trapping of gases and the heat energy from the sun (IPCC, 2007). The change in the climate not only affects the common people but also extremely affects the elderly. Climate change influences the way of life to a greater extent by the following factors like age, residing place, health condition, nature of occupation and their financial status and so on. Extreme temperature in summer, rising sea levels like the unexpected tsunami, cyclone, heavy rainfall, floods, droughts, and sudden earthquakes results poor health condition and threatens the life of the people which may also leads to migration. (Amutha \& Juliet, 2017) Especially the older people are more susceptible to have adverse impact by climate change due to their deteriorated health. This article mainly gives attention to the impact of climate change on elderly on health aspects.

\section{MATERIALS AND METHODS}

This article mainly based on the secondary sources from the national and international articles, journals and reports related to elderly, aging, gerontology, environment and climate change. It covers the impact of global climate change on elderly health in national and international scenario.

\section{IMPACT OF CLIMATE CHANGE ON ELDERLY HEALTH}

Biological ageing of the elderly declines the health status which makes them more vulnerable to get infected and affected during the climate change. Since body metabolism slows down and cell regeneration capacity also becomes less makes them to have chronic health condition and with disabilities. Limited or lack of mobility, difficulties in climbing the stairs and holding or handling the objects leads to adverse effects in time of emergencies like natural calamities especially floods or earthquakes etc. Not only physical functioning of the elderly and also the disabilities in communication (seeing, hearing and speaking) and mental functioning (Alzheimer's disease, senility or dementia) of the elderly make them more vulnerable to get easy access to the utmost difficulties during the change in the climate.

Cox et al., (2006) observed the relationships between the ageing factor, quality of life of the elderly and the coping resources adopted by them to maintain their well-being during the climate change. Extreme weather, high temperature and storm, damage the life of elderly and also it forces them to seek coping resources to prevent from the harm to their health condition. Lack of coping resources from many developing countries makes the elderly to suffer. Not only monetary support but also institutional mechanisms and other informal supports make them to lead a harmless life.

\subsection{Extreme Heat}

Usually the elderly have high risk to their health status during the extreme heat exposure. Illnesses like congestive heart failure, blood pressure, diabetes and other chronic health defects and even death may be the consequences of the extreme heat resulted by the climate change. In some places, the older adults with limited income have limited access to air conditioning since its unit costs high amount which declines their health especially in heart and lungs.(US EPA, 2016) Heat stroke is also another factor worsens the health conditions of the elderly who are in utmost disability.

Costello et al, (2009) compares the impact of heat waves and the cardiovascular conditions of the elderly which increases the risk and threatens their normal routine. He also adds the level of physical ability of the elderly and their immunity. The elderly without protecting them by bed-nets get quick access to infections like malaria and dengue. Natural calamity even worsens the situation of the elderly to get the basic amenities like food and water. Eventually the shortage of basic needs weakens the immune systems of the elderly to fight against any infections since already they have weakened physical ability. 
Kovats and Koppe (2005) say that age has a strong co- relation with physical fitness and illness which makes the elderly more vulnerable to get affected by the heat waves. Therefore, increased temperature increases the mortality rate over the age of 65.

Vidya Soundarajan (2018) highlights that the elderly from the heat waves which are one of the most dangerous silent disasters caused the deaths 22,562 between 1992 and 2015 in India. The government has to protect the most vulnerable people who has increased risk by heat waves will increase the risk of 30 times by 2100 in India.

\section{Strategies to prevent from extreme heat}

The elderly has to take care of themselves by staying out from the sun. Remaining in a cool place; air conditioned is preferable. Shower, bathe or sponge with cool water is advisable. Taking rest in cool place makes them more comfortable. Spending mid-day in a place with airconditioning (movie theatre, mall, and senior centre), avoiding crowds and limiting outdoor exercise during hot weather are most desirable.

\subsection{Extreme winter}

Aging process makes the elderly with less mobility which affects the regular blood supply in their body leads to joint pains in the knees and prevents them to move during extreme winter. The elderly used to suffer with respiratory tract infections, wheezing, asthma and severe chronic obstructive pulmonary disease in winter. Frequent urination i.e., micturition happens to the elderly. Less splinter control makes them bet wetting may create psychological problem to them due to neglect from the family members. Their body resistance and immune system slows down due to aging makes them more vulnerable to get infected with various diseases and even frequent death also occurs at the time of extreme cold. Proper precautionary measures will be provided by the family members and society.

\subsection{Hurricanes}

Hurricane is another one of the dangerous disaster to the vulnerable groups like older people, disabled and the people with chronic illness which leaves mortality as its footprints. Many studies state that the climate change highly affects the older people especially the hurricane Andrew and Hurricane Katrina. This is proved highly by the older people who have very less adaptive capacity to manage the severe situation. Not only less mobility but also the physical and mental weakness increases the high risk to mortality of the elderly. (David Filiberto et al., 2009)

Combs D.L., et al. (1996) draws his attention to the indirect effect of hurricane results heart attack to the elderly during evacuation from the place which gives much mental strain and stress. Hyer et al. (2006) underlined the statistical data proves that Hurricane Katrina left 75 percent of the deaths among the age 60 and 50 percent of older people over the age of 75 . Thus it proves that the elderly has to be given much priority during the natural disaster by the respective sectors.

The studies by Sharkey (2007), Cameron et al. (2009) and Pirard (2005) sheds light to the world that mortality and morbidity as its direct impact to the elderly during the three natural disasters in the world namely European heat wave, hurricane Katrina in the United States in 2005, and the Melbourne bushfires in 2009 which resulted extreme damage to the life of the elderly.

In India, the extremely severe cyclonic storm 'Fani' on May, 2019 blown away thatched houses, swamping towns and villages. This made the death of the elderly woman due to heart attack at a relief shelter in Kendrapara district of Odisha which was reported by the Special Relief Commissioner. Thus, hurricane becomes a very harmful and dangerous natural disaster 
to the life of the elderly which needs more attention by the government for the preventive measures. (India Today, May 3, 2019)

\subsection{Air pollution}

Usually the air pollution harms the vulnerable elderly those already with less immunity. Tropospheric ozone and fine particulates leaves the health effects to the elderly especially those with chronic illness.

The elderly with a history of myocardial infarction or diabetes heightens the death in Chicago with high levels of particulate. Susceptibility to death of those elderly with heart and lung disease becomes an adverse health effect (Bateson \& Schwartz, 2004) which is similarly extreme to those exposed with black smoke also. (Filleul et al., 2004)

United States Environmental Protection Agency (2016) states the effect of climate change with the health of the elderly in tune with poor air quality. A poor air quality increases the pollution and smokes in the air caused by the change in the weather condition and the intense wildfire. The elderly with asthma and chronic obstructive pulmonary disorder (COPD) are prone to have respiratory problems and also increased risk of heart attacks to the elderly with diabetic and obese by the poor air quality. Thus, increased air pollution increases the health disabilities of the elderly becomes one of the important impact of the climate change in the global scenario.

\section{THE IMPACT OF GEOGRAPHICAL LOCATION}

Health of the elderly population and the geographical condition where they live has a strong co relation. In case a particular place prone to have hurricane, tropical storms, and landfall pose threats to the health of the elderly. In urban areas, elderly resides in apartments with lift facility can have difficulty to get basic amenities like food, and medicine during the natural calamities due to sudden loss in the electricity. Less mobility and weakened immune system of the elderly makes them as a victim to get occupied with morbidity and mortality by climate change. (US EPA, 2016)

\section{ILLNESS CAUSED BY CONTAMINATED WATER}

More number of communicable diseases spread by contamination in the drinking water during climate change which poses the high risk to gastrointestinal illnesses to the elderly. Even death could happen to the elderly with less immunity by water contamination. So, usage of pure drinking water will prevent many infections to the elderly in time of any natural hazards.

\section{HEAVY RAINFALL AND FLOOD}

Heavy rainfall makes the elderly to be more prone to get water borne diseases like cholera, malaria, typhoid, diarrhea and other communicable diseases. Due to less immunity they are easily get infected with the diseases. Continuous sickness also makes them less mobility. Floods make the elderly more vulnerable to get affected since they are not able to move very fast during the natural calamity. Many elderly people are left out during the preventive measures since they are not able to cope up with the running water which leads to death also.

According to Age well Foundation in India, the stress caused by natural disaster increases the symptoms of serious health issues in the elderly. Age well volunteers felt very difficult to reach the elderly while distributing the relief material to them especially relief materials hardly contains medicines, often used by old people which impose their health condition at worse condition. 


\section{CONCLUSIONS}

Climate change poses a significant risk to elderly in health aspects. "Prevention is better than cure," thus, the government has to make preventive measures by monitoring the cause and consequences for any change in the climate in the early stage itself will protect and safeguard the health of the elderly. Providing health measures in times of emergency should be preplanned to the elderly by expecting the unexpected, disease surveillance and disease control for the elderly to be strengthened earlier. Climate change is an issue for all of us. The situation is serious but not hopeless. Scholars believe that information is key to ameliorating the effect of climate change on older persons. (Carter et al, 2008) Therefore there is a need for awareness raising and strategic level planning regarding how to take care of the elderly during climate change by various organizations. During natural calamities governmental agencies, NGOs, corporate, organizations and individuals have to rush to the affected areas with relief material and help them with the specific needs of the elderly. While making a relief plan for disaster hit areas, they should think about the elderly as well and attempt to reach out to them on priority basis. National and International Policies to be strengthened and new policy can be made to reduce the vulnerability of the elderly by taking actions to ensure the life of the elderly by providing adequate health and social care.

\section{REFERENCES}

[1] Amutha D., and Juliet M (2017), Impact of Climate Changes on Human Health in India https://ssrn.com/abstract=3071055 or http://dx.doi.org/10.2139/ssrn.3071055

[2] United States Environmental Protection Agency (US EPA, 2016), Climate change and the health of older adults.

[3] Carter, T. R., Fronzek, S., Inkinen, A., Lahtinen, I., Lahtinen, M., Mela, H., Karen, L., O' Brien., Rosentrater L.D., Ruuhela R., Simonsson, L., Terama, E. (2014), Climate Change

Vulnerability Mapping for the Nordic Region, Joint workshop, Stockholm, Summary Report.

[4] Cameron PA., Mitra B, Fitzgerald M, Scheinkestel CD, Stripp A, Batey C, Niggemeyer L, Truesdale M, Holman P, \& Mehra R. (2009). Black Saturday: the immediate impact of the February 2009 bushfires in Victoria, Australia, Med J Aust, 191(1, )11-16. doi: 10.5694/j.1326-5377. 2009. tb02666.x

[5] Combs, D.L., Parrish, R.G., McNabb, Scott, JN., Davis, J. H. (1996), Deaths Related to Hurricane Andrew in Florida and Louisiana, 1992. International Journal of Epidemiology 25: 537-44.

[6] Costello, A., Abbas, M., Allen, A., Ball, S., Bellamy, R., Friel, S., Groce, N., Johnson, A., Kett, M., Lee, M., Levy, C., Maslin, M., McCoy, D., McGuire, B., Montegomery, H., Napier, D., Pagel, C., Patel, J., Jose Antonio, J., de Oliveria, P., Redclift, N., Rees, H., Rogger, D., Scott, J., Stephenson, J., Twigg, J., Wolff, J., Patterson, C. (2009). Managing the health effects of climate change, Lancet, 373, 1693-733.

[7] Cox, Rosenzweig, Solecki, Goldberg and Kinney (2006). Social Vulnerability to Climate change: A Neighborhood Analysis of the Northeast U.S. Mega-region. Rutgers University Community Repository https://doi.org/doi:10.7282/T38P5XQZ

[8] Cyclone Fani bites Odisha, three dead, (May 3, 2019). India Today, Press Trust of India, Bhuvaneshwar/ Kolkata. https://www.indiatoday.in/india/story/cyclone-fani-bites-odishathree-dead-1516340-2019-05-03 
[9] David Filiberto, Wethington, E., Pillemer, K., Wells, M., Wysocki, M., and Jennifer T., P. (2009). Older people and climate change: vulnerability and health effects. American Society on Aging. https://www.asaging.org/blog/older-people-and-climate-changevulnerability-and-health-effects

[10] Fileul,L., Rondeau, V., Cantagrel, A., Dartigues, J., F., Tessier, JF. (2004). Do subject characteristics modify the effects of particulate air pollution on daily mortality among the elderly? Journal of Occupational and Environmental Medicine. 46(11): 1115-22.

[11] Hyer, K., Brown, L.M., Berman, A and Polivka-West, L. (2006). Estabilishing And Refining Hurricane Response Systems For Long- Term Care Facilities. Health Affairs, 25 (5) w407-w411. https://www.healthaffairs.org/doi/pdf/10.1377/hlthaff.25.w407

[12] Intergovernmental Panel on Climate Change (IPCC). (2007a), Summary for Policymakers. In S. Solomon et al., eds., Climate change 2007: The Physical Science Basis Contribution of working group to the Fourth Assessment Report of the Intergovernmental Panel on Climate Change. Cambridge, UK, and Newyork: Cambridge University Press. $\quad$ https://www.ipcc.ch/site/assets/uploads/2018/02/ar4-wg1-spm-1.pdf

[13] Kovats,R. S \& Koppe (2005), Heat waves: Past and future impacts. In Ebi, K.L., J.B. Smith and I. Burton (Eds.), Integration of Public Health with Adaptation to Climate Change: Lessons Learned and New Directions (pp. 136-160.). London, UK: Taylor \&Francis. https://citeseerx.ist.psu.edu/viewdoc/download?doi=10.1.1.192.1201\&rep=rep1\&type=pdf

[14] Margarete L Zalon, (2019), preparing older citizens for global climate change, Vol.14

[15] Pirard P, Vandentorren S, Pascal M, Laaidi K, Tertre AL, Cassadou S, \& Ledrans M. (2005). Summary of the morality impact assessment of the 2003 heat wave in France. Euro Surveillance, 10(7), 153-156.

[16] Sharkey,P. (2007), Survival and Death in New Orleans: An Empirical Look at the Human Impact of Katrina. J Black stud, 37(4), 482-501.

[17] Soundarajan Vidhya, (2018), Is India ready to face the silent disaster? https:// www.downtoearth .org.in/ July, 2018. 